\title{
A Vontade de Sentido na Obra de VIKTOR FRANKL
}

\author{
Ivo Studart Pereira ${ }^{1}$ \\ Universidade Federal do Ceará
}

\begin{abstract}
Neste artigo, procurou-se investigar um ponto central na obra do psiquiatra austríaco, criador da Logoterapia, Viktor Frankl: o conceito de "vontade de sentido". Em nosso entendimento, o tema concerne fundamentalmente à visão de homem que alicerça a referida escola psicológica, constituindo uma categoria chave para uma compreensão mais adequada do pensamento do autor. O traçado lógico do artigo busca relacionar essa categoria à explicitação do caráter autotranscendente da existência humana. Por fim, o texto foi articulado conclusivamente para defender um descentramento do indivíduo em favor do sentido.
\end{abstract}

Descritores: Frankl, Viltor Emil, 1905-1997. Logoterapia. Psicoterapia.

Não é verdade que o homem, propriamente e originalmente, aspira a ser feliz? Não foi o próprio Kant quem reconheceu tal fato, apenas acrescentando que o homem deve desejar ser digno da felicidade? Diria eu que o homem realmente quer, em derradeira instância, não é a felicidade em si mesma, mas, antes, um motivo para ser feliz (Frankl, 1990, p. 11).

\section{Introdução}

psiquiatra austríaco Viktor Emil Frankl (1905-1997) é o fundador da chamada Logoterapia, escola psicológica de caráter fenomenológico, exis-

1 Psicólogo, mestrando em Filosofia pela Universidade Federal do Ceará e bolsista do CNPq. O autor agradece ao Conselho Nacional de Desenvolvimento Científico e Tecnológico, pelo apoio institucional. Endereço eletrônico: ivusp@yahoo.com.br. 


\section{Ivo Studart Pereira}

tencial e humanista, conhecida também como a Psicoterapia do Sentido da Vida ou, ainda, a Terceira Escola Vienense em Psicoterapia. No final dos anos 1920, Oswald Schwarz escreveu, em seu prefácio a um livro de Frankl, que as idéias centrais daquilo que viria a tornar-se a Logoterapia significavam para a "história da psicoterapia o mesmo que a Crítica da Razão Pura para a filosofia" (Frankl, 1981, p. 118).

Aparentemente performática, essa assertiva, no entanto, constitui uma observação sumária mais do que pertinente sobre a obra de Viktor Frankl. Mas, afinal, qual é o sentido de tal afirmação? Kant ilustrou o projeto epistemológico de sua Crítica como uma inversão copernicana: assim como Copérnico ousou retirar a Terra do centro das órbitas planetárias e Kant ousou retirar o objeto do conhecimento do centro mesmo da epistemologia, pode-se afirmar que Frankl livrou a psicoterapia do introspectivismo, desconstruindo a noção de uma autorealização solipsista do centro das motivações primárias do ser humano.

Tal é a tese que pretendemos esboçar neste artigo, ao retomar, pela própria letra de Frankl, suas formulações básicas a respeito da chamada "vontade de sentido", a qual, segundo nosso entendimento, constitui a categoria chave para uma compreensão apropriada da visão de homem da Logoterapia.

\section{O homem e a vontade de sentido}

A formulação a respeito da "vontade de sentido" deve ser entendida historicamente, pelo sistemático descontentamento de Frankl com seus primeiros mentores. Fosse em Sigmund Freud ou em Alfred Adler, a pergunta radical sobre uma orientação última, ou uma motivação primeira para a vida humana parecia insuficiente. Em ambas as escolas, o conteúdo central era inaceitável para a visão de homem da Logoterapia - um psicologismo desonerador da díade ontológica liberdade-responsabilidade e uma visão antropológica estritamente solipsista, no âmbito motivacional.

Em outras palavras, Frankl considerava que tanto o princípio do prazer de Sigmund Freud quanto o status drive de Alfred Adler falham justamente quando oferecem um ponto de vista análogo ao do funcionamento homeostático da redução de tensões em favor da restauração de um equilíbrio interno. Ig- 


\section{A Vontade de Sentido na Obra de VIKTOR FRANKL}

nora-se aí o fato antropológico fundamental da autotranscendência da existência humana, cuja principal manifestação é exatamente a vontade de sentido:

A autotranscendência assinala o fato antropológico fundamental de que a existência do homem sempre se refere a alguma coisa que não ela mesma - a algo ou a alguém, isto é, a um objetivo a ser alcançado ou à existência de outra pessoa que ele encontre. $\mathrm{Na}$ verdade, o homem só se torna homem e só é completamente ele mesmo quando fica absorvido pela dedicação a uma tarefa, quando se esquece de si mesmo no serviço a uma causa, ou no amor a uma outra pessoa. É como o olho, que só pode cumprir sua função de ver o mundo enquanto não vê a si próprio (Frankl, 1991, p. 18).

Frankl reconheceu nas diversas psicologias - sobretudo na psicanálise freudiana e na psicologia individual de Adler - o mesmo vício: a preocupação com um equilíbrio interno, numa perene busca pela cessação de tensão, como objetivo maior da gratificação dos instintos e da satisfação das necessidades, constituindo-se, assim, o fim de toda atividade que envolva a vida. No caso da psicanálise, o próprio princípio da realidade estaria apenas a serviço do princípio do prazer, modulando-o na vida social, mas sempre com o interesse de garanti-lo.

Frankl retoma e desenvolve a tese de Max Scheler (1874-1928) sobre o eudemonismo, no sentido de que não é que o prazer ou a felicidade sejam barreiras à ação moral, mas que, exatamente a reboque da ação moral, o prazer ou a felicidade podem vir a se realizar:

Em geral, o que o homem quer não é o prazer; quer o que quer, sem mais. Os objetos do querer humano são entre si diversos, ao passo que o prazer sempre será o mesmo, tanto no caso de um comportamento valoroso como no caso de um comportamento contrário aos valores. Daí que ... o reconhecimento do princípio do prazer conduza inevitavelmente ao nivelamento de todas as possíveis finalidades humanas. Com efeito, sob esse aspecto, seria completamente indiferente que o homem fizesse uma coisa ou outra.... Se realmente víssemos no prazer todo o sentido da vida, em última análise, a vida pareceria sem sentido. Se o prazer fosse o sentido da vida, a vida propriamente não teria sentido algum (Frankl, 2003, p. 68).

Ou seja, coloca-se aí uma questão ética: se o horizonte das ações humanas é apenas um meio cuja finalidade maior é a gratificação individual, o lugar da alteridade será subsumido num plano direto de validade condicionada a um efeito interno ou a uma reciprocidade necessária. É contra essa psicologia 
homeostática que Frankl se insurge, afirmando que, primariamente, o homem busca o sentido, e que este não tem qualquer relação de necessidade $a$ priori com uma preocupação solipsista de redução de tensão ou de autogratificação. Como se sabe, uma questão crucial no escopo teórico da Logoterapia é a de que o sentido tem um caráter objetivo de exigência e está no mundo, não no sujeito que o experiencia.

Frankl critica também a idéia geral da "hierarquia das necessidades" de Abraham Maslow (1908-1970), afirmando que o preenchimento vertical dessas necessidades não é de muita ajuda, quando o que se procura é encontrar sentido: não se trata de ordenar as necessidades em maiores ou menores, e, sim, de identificar qual delas tem sentido, um objetivo por trás de sua realização. Na Logoterapia, a classificação que Maslow faz das necessidades "não explica o fato de que, quando as mais baixas não são satisfeitas, uma necessidade mais elevada, o desejo de sentido, pode transformar-se na mais urgente de todas" (Frankl, 2005, p. 27).

É nesse contexto que retomamos nossa epígrafe. A distinção kantiana entre "felicidade" e "ser-se digno" dessa felicidade ilustra exatamente o argumento contra essa modalidade de individualismo identificada nos mecanismos homeostáticos das psicologias, segundo Frankl. Quem busca a "felicidade" em si, parece desejá-la de modo absoluto, incondicional e individual, sem que nela esteja implicada uma idéia de "razão" para ser feliz.

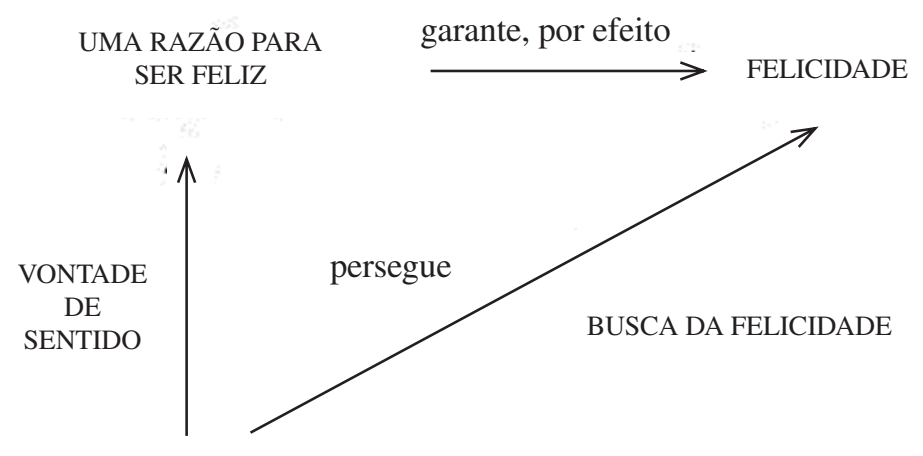

Figura 1. Extraído de: Frankl (1988, p. 34) 
Essa "razão", no entanto, está implicada como efeito da realização de um sentido, não como algo alcançável por si mesmo. Ser-se "digno" da felicidade é um efeito colateral da realização de sentido que é, sim, o fim em si, independentemente dos efeitos que acarreta. Isto é, a vontade de sentido orienta para uma realização de sentido, a qual acaba por prover uma razão para se ser feliz. Com uma razão para se ser feliz, a felicidade surge automaticamente como efeito colateral.

Por esse raciocínio, a Logoterapia propõe, por exemplo, um olhar diferente sobre as adicções. A frustração ou o vazio existencial - a estagnação da realização dos sentidos particulares da vida - podem levar o indivíduo a perseguir os efeitos de prazer diretamente, pela bioquímica. Um alcoolista sentirá prazer como efeito da depressão de seu lobo frontal: ele terá uma causa por que sentir prazer, mas não terá uma razão. Assim como alguém que chora ao cortar cebolas, em que há uma causa, mas não uma razão. As causas - sempre de natureza psicológica ou bioquímica (nunca noológicas ou espirituais) - são buscadas na frustração da orientação original para o sentido.

Por conseguinte, a Logoterapia nega-se a aceitar as noções de "autorealização", de "felicidade", de "prazer" ou de "poder" como objetos da busca última do ser humano. O entendimento das vontades de "prazer" e de "poder" como motivações primárias resulta de um terreno de observação das motivações autocêntricas tipicamente neuróticas nas quais principalmente Freud e Adler se basearam (Frankl, 1988, p. 36). Esse padrão neurótico está ilustrado na figura1, em que se vê um desvio para uma busca "direta" da felicidade.

Essa busca "direta" de uma felicidade incondicional - que a Logoterapia entende como uma motivação possivelmente patogênica - também deve ser entendida segundo aquilo que Frankl denominou "princípio auto-anulativo" (Frankl, 1988, p. 33), segundo o qual quanto mais o sujeito se propõe a perseguir uma idéia acabada e auto-suficiente de "bem" - como a felicidade, o prazer ou o sucesso, por exemplo, em detrimento da realização de sentido -, mais esse sujeito se desviará desse intento. Assim, uma tal "busca da felicidade", de uma auto-realização ensimesmada, acabaria por constituir uma motivação potencialmente neurótica. "Não se deve buscar a felicidade" é uma máxima da Logoterapia, tendo em vista que, na medida em que houver uma razão para a felicidade, ela decorrerá espontânea e automaticamente. A máxi- 


\title{
Ivo Studart Pereira
}

ma logoterapêutica subseqüente é: "Não se pode perseguir a felicidade", pois, na medida em que se faz da felicidade um objeto motivacional, ela passa a se constituir em objeto de atenção, perdendo-se de vista a razão para ser feliz, o que, conseqüentemente, afastaria o sujeito da felicidade. Frankl entende, portanto, uma excessiva preocupação com a auto-realização como um possível sinal de uma frustração da vontade de sentido, fazendo uso da metáfora do bumerangue, que só volta ao caçador que o atirou se seu alvo não tiver sido atingido. Da mesma forma, o homem só se volta para si como centro maior de suas preocupações se tiver falhado na busca de sentido.

\begin{abstract}
A auto-realização não constitui a busca última do ser humano. Não é sequer sua intenção primária. A auto-realização, se transformada num fim em si mesmo, contradiz o caráter autotranscendente da existência humana. Assim como a felicidade, a auto-realização aparece como efeito, isto é, o efeito da realização de um sentido. Apenas na medida em que o homem preenche um sentido lá fora, no mundo, é que ele realizará a si mesmo. Se ele decide realizar a si mesmo, ao invés de preencher um sentido, a auto-realização perde imediatamente sua razão de ser (Frankl, 1988, p. 38).
\end{abstract}

Chegamos, então, à tese de que tanto o princípio do prazer (a que Frankl chama "vontade de prazer") quanto o status drive (ou "vontade de poder") são meras derivações da motivação primária do ser humano - a vontade de sentido, que é o esforço mais básico do homem para encontrar e realizar sentidos e propósitos: "Nós chamamos de vontade de sentido simplesmente àquilo que é frustrado no homem sempre que ele é tomado pelo sentimento de falta de sentido e de vazio" (Frankl, 1991, p. 25). Mas como se justificaria essa derivação? Ora, se nem o poder, nem o prazer, nem sequer a felicidade em si ou as outras noções similares de "bem" podem ser considerados, antropologicamente, como fins em si mesmos, há que reposicionar essas noções a partir da vontade de sentido, já que este, sim, se constituiria como o "fim", como o "bem”, não deduzido e nem racionalizável a priori. 


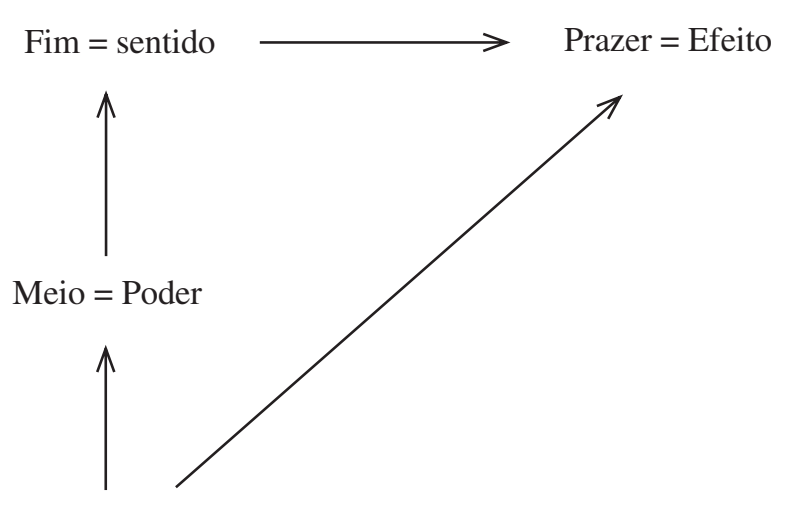

Figura 2. Extraído de Frankl (1988, p. 36)

Na figura 2, esboça-se a idéia geral dos problemas encontrados por Frankl em Freud e em Adler. Centrando-se na tese da "vontade de sentido", reposicionam-se o prazer como efeito colateral da realização de um sentido e o poder como um instrumento, um meio ocasional de se facilitar essa realização. Como mostra a ilustração, no reposicionamento, nem poder, nem prazer se fixam como fins. Cabe lembrar que Frankl rejeita a concepção da vontade de sentido nos termos de um instinto, porque caberia a associação entre instinto como mecanismo natural de direcionamento da redução de tensão interna, contradizendo justamente a idéia logoterapêutica da finalidade intrínseca da realização do sentido, que não tem relações a priori de necessidade com um propósito ou uma satisfação individual: "Assim se compreenderá o que é mais contrário à moralidade: todo cálculo sobre o efeito de uma boa ação, toda especulação sobre o êxito de uma boa obra que traga lucros" (Frankl, 1978, p. 270).

Através do conceito de "noodinâmica", Frankl também critica as concepções de saúde mental que se valem de um ideal semelhante ao do equilíbrio homeostático, afirmando que, existencialmente, uma certa quantidade de tensão é um pré-requisito indispensável à saúde psíquica:

O de que o ser humano realmente precisa não é um estado livre de tensões, mas antes a busca e a luta por um objetivo que valha a pena, uma tarefa escolhida livremente. $\mathrm{O}$ de que ele necessita não é a descarga de tensão a qualquer custo, mas 


\section{Ivo Studart Pereira}

antes o desafio de um sentido em potencial à espera de seu cumprimento. $\mathrm{O}$ ser humano precisa não de homeostase, mas daquilo que chamo de "noodinâmica"... Ouso dizer que nada no mundo contribui tão efetivamente para a sobrevivência, mesmo nas piores condições, como saber que a vida da gente tem um sentido. Há muita sabedoria nas palavras de Nietzsche: "Quem tem um por que viver pode suportar quase qualquer como" (Frankl, 1985, pp. 95-96).

Contra a hipótese do caráter vão das realizações de sentido, tão bem defendida pelos existencialistas ateus como, por exemplo, Albert Camus (1913-1960), em seu célebre $O$ mito de Sísifo, Frankl reafirma sua tese sobre a estabilidade do ser-passado: ter-sido é a forma mais segura de se ser. Todas as escolhas que transformaram uma única possibilidade de sentido em ser, condenando todas as outras ao não-ser, constituem um patrimônio inalienável da pessoa humana, salvas da transitoriedade da vida. Essa foi uma das aproximações teóricas de Frankl com Martin Heidegger (1889-1976). Numa visita colega vienense, desejando sublinhar o "parentesco de opiniões" sobre o tema, Heidegger escreveu no verso de uma foto dedicada a Frankl: "O passado se distancia. O que foi se aproxima" [Das Vergangene geht. Das Gewesene kommt] (Frankl, 1981, p. 112).

A partir desse olhar sobre o ser humano, pode-se pensar um novo eixo de avaliação da existência. A idéia de que a orientação primária do homem está pautada numa busca última pelo prazer, ou pelo poder, nos leva a um critério da ordem da dicotomia "fracasso e êxito"; é essa a dimensão do Homo sapiens, que se representa no eixo horizontal da figura 3. Na dimensão do Homo patiens, representada no eixo vertical, no entanto, o critério passa a ser o de realização ou não da vontade de sentido, instaurando-se a polaridade entre satisfação e desespero. A Logoterapia concebe o Homo patiens como o homem que cumpre com sua orientação ontológica para a realização de sentido, não obstante o sofrimento e apesar do fracasso, posto serem dois critérios não excludentes de análise. Através do desmembramento em dois eixos, é possível entender por que pode haver satisfação apesar do fracasso e desespero apesar do êxito. 


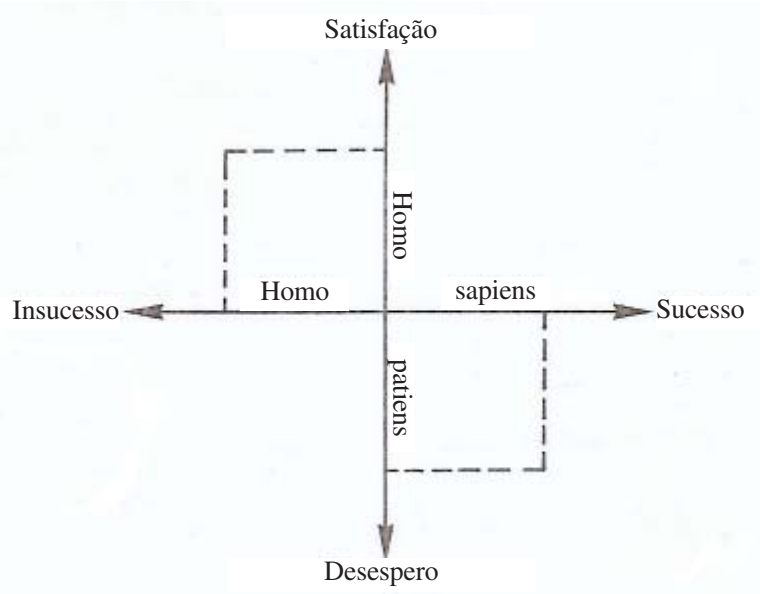

Figura 3: (Frankl, 1981, p. 52)

A título de ilustração, Frankl (1981, p. 53) cita a significativa taxa de suicídios entre estudantes na Universidade Estadual de Idaho, a expressiva clientela de executivos bem-sucedidos que se queixavam de um "sentimento abismal de falta de sentido" no Centro de Terapia do Comportamento de Nova Iorque e a sugestiva parcela de ex-alunos de Harvard que procuravam atendimento clínico com a mesma queixa. Essas pessoas estariam situadas no quadrante inferior direito da figura 3. Na polaridade oposta - no canto superior esquerdo -, Frankl menciona depoimentos de alguns presidiários, que lhe escreveram dizendo, apesar da miséria do passado e do fracasso do presente, ter encontrado o sentido da própria vida, como o prisioneiro de número 049246, da Penitenciária Estadual de Segurança Máxima da Flórida, que lhe endereçou a seguinte mensagem: "Aqui, na prisão - aqui, a apenas cem metros da cadeira elétrica -, há sempre mais possibilidades de nos desenvolvermos para além de nós mesmos. Eu preciso dizer que, de alguma forma, estou hoje mais feliz do que nunca" (Frankl, 1981, p. 54). 


\section{Ivo Studart Pereira}

\section{Conclusão}

Na medida em que compreende a existência-espiritual humana como "autotranscendente", Frankl deixa claro que o sentido potencial de uma situação vivida não guarda relações de necessidade com qualquer compromisso com a autoconservação ou com um ideal direto de enriquecimento egóico solipsista. Ele reposiciona as noções de "bem" decorrentes de uma ética contemporânea cujos ideais parecem ser uma felicidade individualizada e um prazer ensimesmado, recolocando-os num patamar de efeitos colaterais. Entre prazer ou felicidade e ação humana, há uma idéia de dignidade ou merecimento que só é inteligível quando a realização do sentido aparece como fim em si mesma: só a reboque da satisfação encontrada desse modo é que a felicidade e o prazer se fundamentam como dignos de ser.

Assim, podemos falar de um "descentramento" do indivíduo em favor do sentido, já que uma das conseqüências da teoria motivacional da Terceira Escola Vienense é a de que o sujeito só se singulariza na medida em que cumpre sua orientação ontológica para tornar significativa a própria vida. A busca desse sentido - que tem um caráter objetivo, fundando-se no mundo, não no sujeito - constitui, na Logoterapia, o fim último de toda a atividade que envolve a existência humana. A analogia crítica com os modelos homeostáticos de funcionamento é bastante rica aí. É nesse contexto que podemos entender mais apropriadamente essa face da "revolução copernicana" na psicologia: uma idéia de ser humano marcado pela autotranscendência se confunde com um ideal de dever-ser que não se esgota em leituras psicológicas que fundem o ser humano no prazer ou no poder.

Pereira, I. S. (2007). Viktor Frankl's will to meaning. Psicologia USP, $18(1), 125-136$

\footnotetext{
Abstract: The present paper aims to investigate a central point in the opus of Austrian psychiatrist Viktor Frankl: the "will to meaning" concept. We believe that this concept constitutes the cornerstone of the anthropological view of Logotherapy. We also aim at showing how decisive that category is for a proper understanding of the author's
} 


\section{A Vontade de Sentido na Obra de VIKTOR FRANKL}

thought. Our logic path has led us to a discussion over the selftranscendent quality of human existence and its relation to the will to meaning. Finally, we stand for the existence of a transposition of the individual in behalf of meaning in Logotherapy theory.

Index terms: Frankl, Viktor Emil. Logotherapy. Psychotherapy.

Pereira, I. S. (2007). La volonté de Sens dans 1’Oeuvre de Viktor Frankl. Psicologia USP, 18(1), 125-136.

Résumé: Cet article examine un point central dans l'oeuvre du psychiatre autrichien Viktor Frankl, créateur de la Logothérapie: le concept "volonté des sens". Il nous semble que ce thème constitue la base d'une visée anthropologique de la Logothérapie et que cette catégorie est bien caracteristique de la pensée de l'auteur. Le parcours développé ici a mené a une discussion sur l'individu-transcendante comme une qualité de l'existence humaine. Bref, on arrive à conclure qu'il existe une transposition de l'individu vers le sens d'après la Logothérapie.

Mots clés: Frankl, Viktor Emil. Logothérapie. Psychothérapie.

\section{Referências}

Frankl, V. E. (1978). Fundamentos antropológicos da psicoterapia (R. Bittencourt, trad.). Rio de Janeiro: Zahar.

Frankl, V. E. (1981). A questão do sentido em psicoterapia (J. Mitre, trad.). Campinas, SP: Papirus.

Frankl, V. E. (1985). Em busca de sentido (W. Schlupp, trad.). Petrópolis, RJ: Vozes.

Frankl, V. E. (1988). The will to meaning. New York: Meridian Books. (Trechos neste trabalho traduzidos por Ivo Studart Pereira)

Frankl, V. E. (1990). Psicoterapia para todos (A. Allgayer, trad.). Petrópolis, RJ: Vozes.

Frankl, V. E. (1991). A psicoterapia na prática (C. M. Caon, trad.). Campinas, SP: Papirus. 


\section{Ivo Studart Pereira}

Frankl, V. E. (2003). Psicoterapia e sentido da vida (A. M. Castro, trad.). São Paulo: Quadrante.

Frankl, V. E. (2005). Um sentido para a vida (V. H. Lapenta, trad.). Aparecida, SP: Idéias e Letras.

Recebido em: 9/04/2007

Aceito em: 7/05/2007 